\title{
Proliferative Leukemic Retinopathy with Bilateral Exudative Retinal Detachments and Optic Disc Swelling in A Patient with Acute Lymphoblastic Leukemia
}

\author{
Linda Susanti ${ }^{1}$, Safaruddin Refa ${ }^{1}$, Mirza Metita ${ }^{1}$, Nadia Artha Dewi ${ }^{1}$ \\ ${ }^{1}$ Department of Ophthalmology, Faculty of Medicine, Universitas Brawijaya \\ dr. Saiful Anwar General Hospital, Malang, East Java, Indonesia
}

\section{ABSTRACT}

Introduction: To report a patient with acute lymphoblastic leukemia (ALL) who developed proliferative leukemic retinopathy with bilateral exudative retinal detachments and optic disc swelling.

Case Report: A 11-year-old girl diagnosed with ALL-L2 on maintenance chemotherapy presented with severe blurred vision in both eyes for the past 1 year. Her visual acuity was 0,5/60 for both eyes. Slit-lamp examination of the anterior segment was found normal. Dilated fundus examination revealed tortuous retinal vessels, retinal haemorrhage, retinal and optic disc neovascularizations, optic disc with indistinct margins, and total retinal detachments in both eyes, as well as vitreous haemorrhage in the left eye. The ultrasonography examination revealed bilateral subretinal fluid.

Discussion: The patient was diagnosed with bilateral proliferative leukemic retinopathy with exudative retinal detachments and infiltrative optic neuropathy, and left eye vitreous haemorrhage due to ALL. Conservative treatment was given. She continued the maintenance chemotherapy from pediatric department. After 2 months follow up, the visual acuity did not improve although retinal detachments were reduced. There were atrophic changes at the retina of her both eyes.

Conclusion: It was reported a rare case of proliferative leukemic retinopathy with bilateral exudative retinal detachments and optic disc swelling. Early recognition and treatment is crucial to improve prognosis.

Keywords: Acute lymphoblastic leukemia (ALL), proliferative retinopathy, exudative retinal detachment, optic disc swelling.

Cite This Article: SUSANTI, Linda et al. PROLIFERATIVE LEUKEMIC RETINOPATHY WITH BILATERAL EXUDATIVE RETINAL DETACHMENTS AND OPTIC DISC SWELLING IN A PATIENT WITH ACUTE LYMPHOBLASTIC LEUKEMIA. International Journal of Retina, [S.I.], v. 2, n. 2, sep. 2019. ISSN 2614-8536. Available at: https://www.jiretina.com/index.php/ijretina/article/view/95

https://doi.org/10.35479/ijretina.2019.vol002.iss002.95

\section{INTRODUCTION}

${ }^{*}$ Correspondence to: Linda Susanti,

Department of Ophthalmology, Faculty of Medicine Universitas Brawijaya, Malang lindasusanti191180@gmail.com
Ophthalmologic findings can be seen in acute lymphoblastic leukemia due to leukemic cell invasion or hematological disturbances. Although these findings are detected in the active phase of the disease, they can also be the first sign of a leukemic relapse. All parts of the eye including retina, optic nerve, and choroid can be effected.1 While microvascular changes, intraretinal and vitreous hemmorrhage and leukemic infiltrates are commonly seen, exudative retinal detachment is a less common. $2,3,4$
Proliferative retinopathy occurs due to chronic nonperfusion of a large areas of the retina that predisposes to retinal neovascularization, and in acute leukemias has been rarely report. Only three case reports in literature where acute lymphoblastic leukemia (ALL) patients had proliferative retinopathy. .,6,7 $^{5}$ Here, we present a case of proliferative retinopathy with bilateral exudative retinal detachment and optic disc swelling in a child with ALL who was under maintenance phase of chemotherapy. 


\section{CASE REPORT}

A 11-year-old girl has complained blurred vision on her both eyes gradually since 1 year ago and getting worse in the last 2 months. She had been diagnosed with L2 subtype-ALL since 1 year ago and on maintenance phase chemotherapy. She has been never examined by an ophthalmologist before. On ophthalmological examination, visual acuities were counting finger at half meter in both eyes with normal pupil reaction without an afferent pupillary defect. Intraocular pressures (IOPs) were $16 \mathrm{~mm} \mathrm{Hg}$ in the right eye and $18 \mathrm{~mm} \mathrm{Hg}$ in the left eye by applanation tonometry.
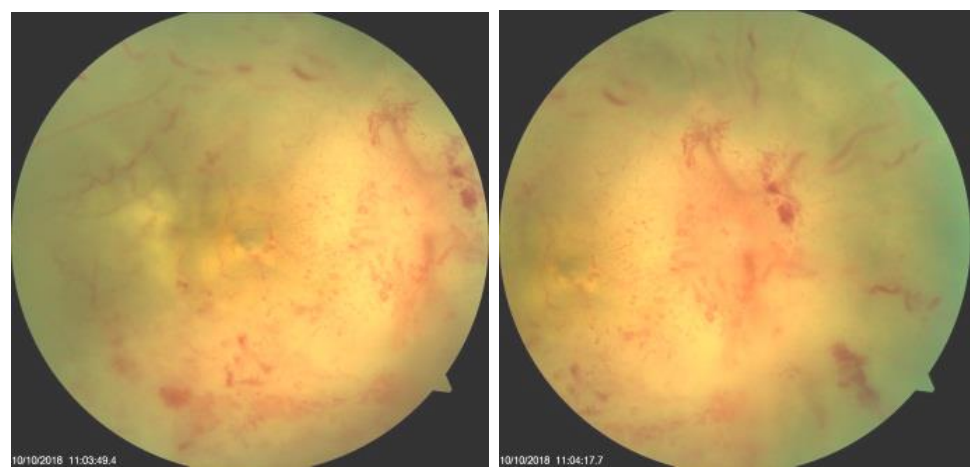

Figure 1. Fundus photographs of right eye.

There was total exudative retinal detachment with optic disc swelling.

Anterior segment examination was normal. Dilated fundus examination revealed dilated and tortuous retinal vessels, intraretinal haemorrhage, exudates, and swollen optic disc with indistinct margins in both eyes. There were bilateral retinal detachment which involve all retina areas including macula and optic disc (Figure 1 and 2). Additionally, there was vitreous hemorrhage on LE (Figure 2).
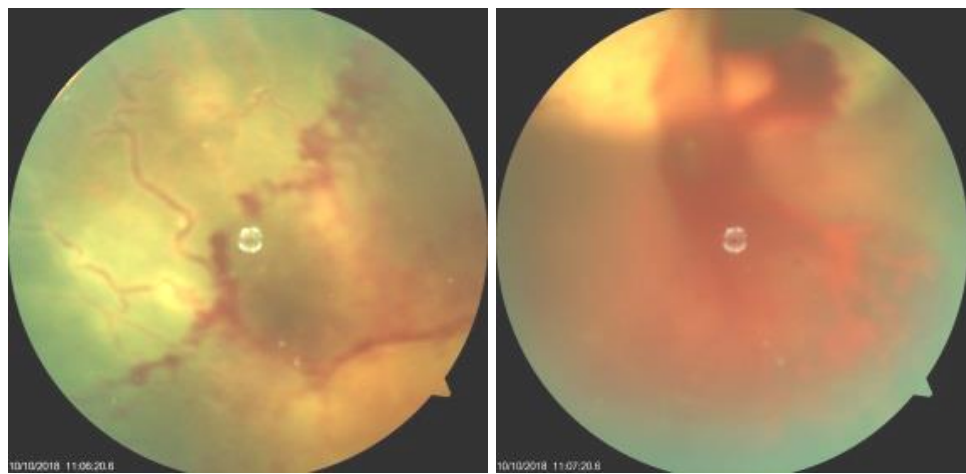

Figure 2. Fundus photographs of left eye, showing total exudative retinal detachment with optic disc swelling and vitreous hemorrhage.

On USG examination, there were subretinal fluid on both eyes and vitreous haemorrhage on left eye (Figure 3). OCT could not be done because the patient had difficulty on eye fixation at the time of examination. Other systemic examination findings were normal and blood tests were within normal range. There was no leukemic blasts in bone marrow aspirate.

The patient was advised to continue treatment of ALL according to the chemotheraphy program from pediatric department. She was planned to get intravenous vincristin $1,5 \mathrm{mg} / \mathrm{m} 2$ and dexamethason tablet $6 \mathrm{mg} / \mathrm{m} 2$ per six weeks, methotrexate tablet $20 \mathrm{mg} / \mathrm{m} 2$ per week, and 6 -mercaptopurine tablet $50 \mathrm{mg} / \mathrm{m} 2$ per day. 


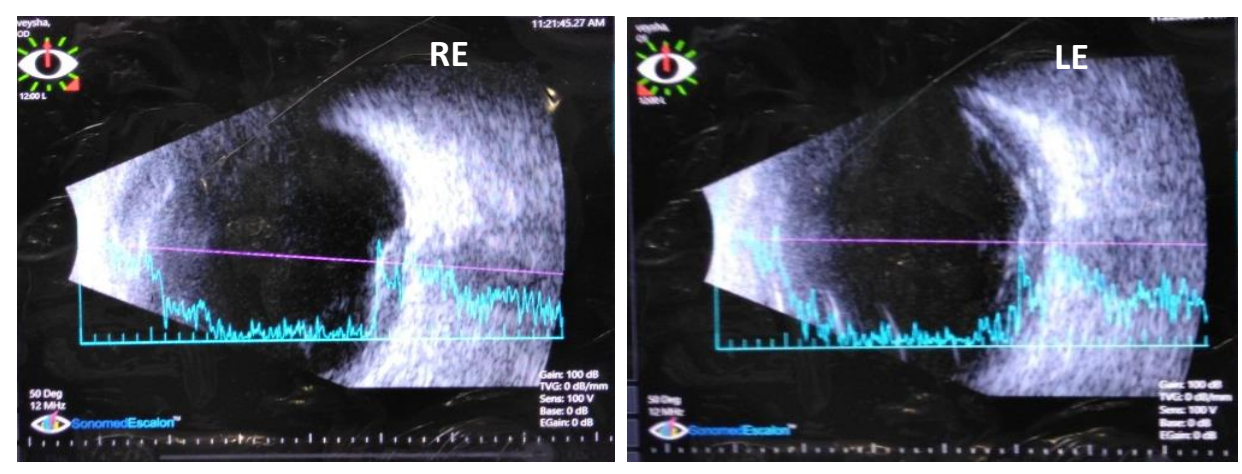

Figure 3. Right and left eye USG results. There was subretinal fluid in both eyes.

At the 1 month follow up, there were no changes in visual acuity and anterior segment conditions. The exudative retinal detachments slightly reduced. The tortuos retinal vessel appeared more clearly than before and denoted neovascularizations on the optic disc and retina of her both eyes. Vitreous haemorrhage on let eye reduced (Figure 4).
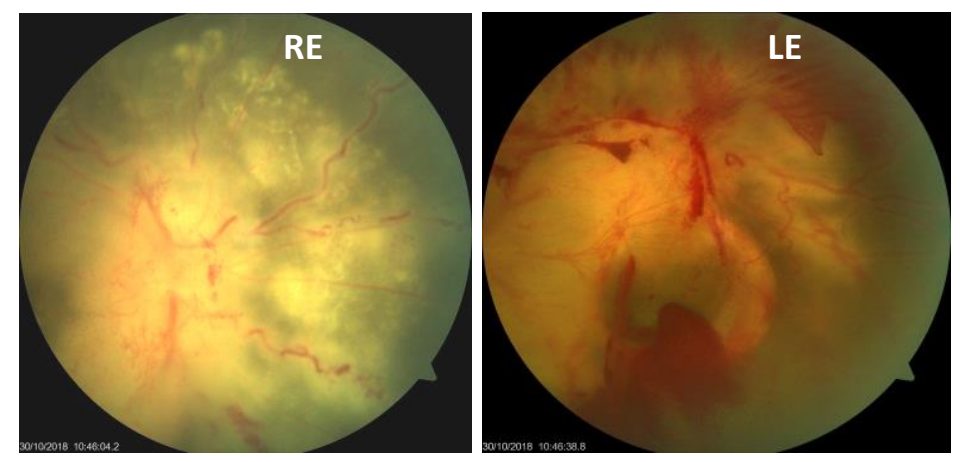

Figure 4. Fundus photographs at 1 month follow up. The tortuos retinal vessel appeared more clearly and showed neovascularizations on the optic disc and retina of both eyes.
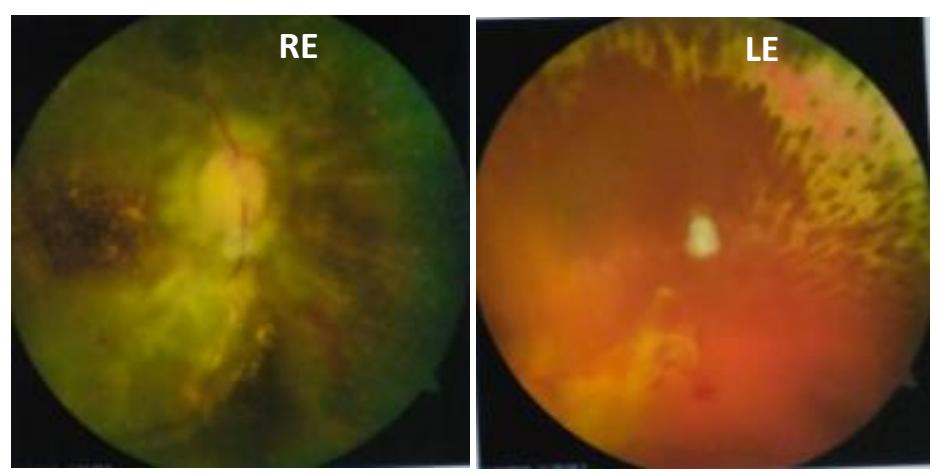

Figure 5. Fundus photographs at 2 month follow up. The exudative retinal detachments reduced on both eyes, showing atrophic changes at the retina areas.

At the 2 month follow up, the visual acuity did not improve although retinal detachments were reduced. There were atrophic changes at the retina of her both eyes. The right funduscopic findings showed focal hyperpigmentation areas including at the macula. Additionally, the optic disc swelling resolved and appeared pale colour. Therefore, the vitreous hemorrhage on her left eye still persisted (Figure 5). 


\section{DISCUSSION}

Ocular manifestations are frequent and can be seen in up to $90 \%$ of acute leukemia patients, either prior to the systemic diagnosis or during the course of the disease. The most common site of ophthalmic involvement is the retina. ${ }^{48-10}$ Common retinal manifestations of ALL include venous dilatation and tortuosity, white centered retinal hemorrhages and cotton wool spots. ${ }^{10}$ Serous retinal detachment and optic disc swelling are less common. ${ }^{4,10}$ Proliferative retinopaty in acute leukemia has also been rarely report. Only three case reports in literature where acute lymphoblastic leukemia patients had proliferative retinopathy. ${ }^{4,5,6}$

In this case, we present a child with proliferative leukemic retinopathy with bilateral exudative retinal detachment and infiltrative optic neuropathy, as well as vitreous hemorrhage on left eye. The diagnosis was based on history taking, dilated funduscopy, and USG examination.

Proliferative retinopathy occurs due to chronic nonperfusion of a large areas of the retina that predisposes to retinal neovascularization and creation of fibrovascular membranes that eventually create traction and bleed. Chronic leukemia develops proliferative retinopathy due to long-standing retinal nonperfusion. On the other hand, acute leukemia due to short duration of presentation do not develope proliferative retinal changes. ${ }^{4}$ However, in this case, we found neovascularization at the retina and optic disc. This condition could explain what the cause of vitreous hemorrhage on left eye whereas the blood tests were within normal range. Chemoterapeutic agents in addition to the disease process itself could have worsened microangiopathy leading to much severe ischemia. ${ }^{5}$

Exudative retinal detachment, has been reported in only a few cases of acute lymphoblastic leukemia world-wide, especially as a presenting sign of the disease, complication during the course of the disease, or the first sign of relapse. ${ }^{3,10-12}$ Most of the reported cases of ALL with serous retinal detachment have involved younger patients. It may develop as a result of choroidal involvement with yellowish choroidal infiltrates, usually located in the polus posterior. ${ }^{12-14}$ Leukemic infiltration into the choroid is thought to decrease blood flow in the choriocapillaries and cause ischemia of the overlying retinal pigment epithelium, which disrupts the intercellular tight junction and causes exudative retinal detachment. As a result, incompetence of the outer blood-retinal barrier leads to subretinal accumulation of choroidal fluid. ${ }^{3}$ In this case, we obtained the exudative retinal detachments with yellowish choroidal infiltrates. All retina areas including optic nerve head and macula were involved.

In the current case, bilateral exudative retinal detachments was accompanied by bilateral optic disc swelling. Based on literatures, only two case of ALL has been reported previously, in which optic disc swelling cooccurred with SRD.,15 Optic nerve infiltration may cause optic disc swelling by compression of nerve fibers and disruption of axoplasmic flow. ${ }^{16}$ Optic disc may also be swollen due to venous outflow obstruction by perivascular leukemic cells. ${ }^{17}$

There is no standard treatment regimen in posterior segment involvement due to leukemic infiltration. ${ }^{18}$ The basis of the treatment is systemic chemotherapy, and there are patients reported as chemotherapy alone being successful. ${ }^{11-13}$ In some other centers however, the bloodretinal barrier was thought to block the chemotherapy to pass into the eye, so additional local chemotherapy or radiotherapy was used. Vitrectomy is needed if traction sets in, which is threatening or involving the macula or if massive vitreous hemorrhage occurs. ${ }^{7}$ Enucleation is also recommended if there is painful glaucoma that refractory to medical treatment. ${ }^{18}$

A recent study revealed that $96 \%$ of children with ALL died within 28 months of onset of ocular signs. Of those ALL patients with ocular manifestations, $82 \%$ had CNS leukemia. The five-year survival rate of patients with ophthalmic manifestations was reported to be $21.4 \%$. This survival rate was significantly lower than those who lacked ophthalmic manifestations (45.7\%). ${ }^{19}$

Our patient did not undergo baseline retinal screening after diagnosis of ALL. When she first examined at our clinic, we found an advanced retinal abnormalities. The exudative retinal detachments had involved all area of the retina including the macula and optic disc, associated with proliferative retinal phase and vitreous haemorrhage on left eye. Therefore, this condition denoted a poor visual prognosis for the patient. We managed the patient with conservative therapy. We advised the patient to continue the chemotherapy program according to pediatric department. We did not plan to undergo vitrectomy for her left eye because of her general condition and also her poor visual prognosis. Thereafter, the disease was progressed and she never controlled to the clinic. The patient passed away at the seventh month after the last follow up. 


\section{CONCLUSION}

A rare case of proliferative leukemic retinopathy with bilateral exudative retinal detachments and infiltrative optic neuropathy has been reported in a patient with ALL. This report points out the importance of ophthalmological examinations in leukemia patients. Although the prognosis of leukemia patients with ocular manifestations is poor, early diagnosis and prompt treatment can preserve the patient's vision.

\section{REFERENCES}

1. Sharma T, Grewal J, Gupta S, Murray PI. Ophthalmic manifestations of acute leukaemias: the ophthalmologist's role. Eye (Lond). 2004;18:663-672.

2. Reddy SC, Jackson N. Retinopathy in acute leukaemia at initial diagnosis: correlation of fundus lesions and haematological parameters. Acta Ophthalmol Scand. 2004:82:81-85.

3. Stewart MW, Gitter KA, Cohen G. Acute leukemia presenting as a unilateral exudative retinal detachment. Retina. 1989; 9: 110-114.

4. Kiziloglu OY, Gedar Totuk OM, Nestanoglu N. Recurrence of Acute Lymphoblastic Leukemia Manifesting as Serous Retinal Detachments and optic disc swelling. International Ophthalmology. 2017:1-6. DOI: 10.1007/s10792-017-0648-6.

5. Wiznia RA, Rose A, Levy AL. Occlusive microvascular retinopathy with optic disc and retinal neovascularization in acute Lymphocytic Leukemia. Retina. 1994;14:253-5.

6. De Juan E, Green WR, Rice TA, Erozan YS. Optic disc neovascularization associated with ocular involvement in acute lymphocytic leukemia. Retina. 1982;2:61-4.

7. Kumawat $D$, Kumar V, Sahay $P$, Chandra P. Bilateral proliferative retinopathy in B-cell acute lymphoblastic leukemia. Indian Journal of Ophthalmology. 2018; 66(1):148-151.

8. Talcott KE, Garg RJ, Garg SJ. Ophthalmic manifestations of leukemia. Curr Opin Ophthalmol. 2016;27:545-551.

9. Kincaid MC, Green WR. Ocular and orbital involvement in leukemia. Surv Ophthalmol, 1983;27:211-232, ISSN 0039-6257.

10. Javier Mateo, Francisco J. Ascaso, Esther Núñez, Carlos Peiro, Gonzalo González and José A. Cristóbal. Ophthalmological Manifestations in Acute Lymphoblastic Leukemia, Novel Aspects in Acute
Lymphoblastic Leukemia, Dr. Stefan Faderl (Ed.), (2011) ISBN: 978-953-307-753-6, InTech,Available from:http://www.intechopen.com/books/novelaspects-in-acute-ymphoblastic-

leukemia/ophthalmologicalmanifestations-in-acutelymphoblastic-leukemia

11. Kim J, Chang W, Sagong M. Bilateral serous retinal detachment as a presenting sign of acute lymphoblastic leukemia. Korean J Ophthalmol. 2010;24(4):245-248, ISSN 1011-8942.

12. Yang HK, Yu HG. Acute lymphoblastic leukemia manifesting as acute Vogt-Koyanagi-Harada disease. Korean J Ophthalmol. 2009;23(4):325-328, ISSN 10118942.

13. Miyamoto K, Kashii S, Honda Y. Serous retinal detachment caused by leukemic choroidal infiltration during complete remission. $\mathrm{Br} J$ Ophthalmol. 2000;84:1318-9, ISSN 0007-1161.

14. Malik R, Shah A, Greaney MJ, et al. Bilateral serous macular detachment as a presenting feature of acute lymphoblastic leukemia. Eur J Ophthalmol. 2005;15:284-286, ISSN 1120-6721.

15. Zimmermann A, Weinand F, Lorenz B. Unilateral loss of visual function with edema of the optic nerve in a 35year-old male patient. Ophthalmologe. 2010;107:10721076.

16. Chan JW. Compressive and infiltrative optic neuropathies. In: Chan J (ed) Optic nerve disorders, diagnosis and management. Springer, New York, 2007: 114-115.

17. Weaver RG Jr, Chauvenet AR, Smith $T J$, et al. Ophthalmic evaluation of long-term survivors of childhood acute lymphoblastic leukemia. Cancer. 1986;58:963-968

18. Karaman S, Gülkilik G, Vural S, Aydın B, Polat N, et al. Serous Retinal Detachment in a Pediatric Case with Acute Lymphoblastic Leukemia as a First Sign of Leukemic Relapse. J Hematol Transfus. 2014;2(1):1014.

19. Ohkoshi K, Tsiaras WG. Prognostic importance of ophthalmic manifestations in childhood leukaemia. $\mathrm{Br}$ J Ophthalmol. 1992;76:651-5.

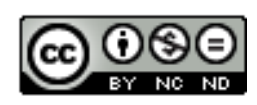

This work licensed under Creative Commons Attribution 